\title{
The pathophysiology of aging bone jaw: primary and secondary prevention
}

\author{
G Campisi \\ From de Senectute: Age and Health Forum \\ Catanzaro, Italy. 5-7 December 2009
}

The skeleton is composed of approximately 200 bones, and it is the backbone of our body along with ligaments and joints. The bone is not a static but a dynamic structure, constantly reshuffling, that may suffer fractures due to trauma, despite their particular hardness and strength. Complex physiologic mechanisms, sometimes with the help of surgery, can lead to bone repairing. In the elderly, often, the skeletal system can be affected by osteoporosis, a "silent disease" that causes fragile bones especially of the vertebrae and femur; its contributing factors are menopause (in women), smoking, nutritional deficiencies, systemic diseases or prolonged use of drugs.

The masticatory apparatus and its main functions of chewing, speech and swallowing are affected by osteoporosis with the same percentage of the skeleton, and in many studies the relationship between systemic osteoporosis and loss of alveolar bone and teeth has been linked [1].

For reducing the health impact and social of a disease mostly asymptomatic, progressive and highly disabling condition such as osteoporosis, promoting health and raising public awareness of the benefits associated is a priority, with the adoption of healthy lifestyles in a vision that embraces the entire course of life. Osteoporosis prevention should start at the pediatric and adolescent age thanks to the intake of appropriate foods (calcium, vitamin D) that are absorbed by the complete organism and are involved in the consolidation of bone mass. It should be a distinguished primary prevention (to prevent the fracture) from secondary prevention (to avoid re-injury after a first fracture event).

Although many points are still to be clarified in terms of both therapeutic and physiological profiles, early diagnosis and implementation of preventive rules are

Department of Oral Sciences, University of Palermo, Palermo, Italy necessary for reducing the risk of fractures also in the maxillary bone.

Published: 19 May 2010

\section{Reference}

1. Vlasiadis KZ, Damilakis J, Velegrakis GA, Skouteris CA, Fragouli I, Goumenou A, Matalliotakis J, Koumantakis EE: Relationship between BMD, dental panoramic radiographic findings and biochemical markers of bone turnover in diagnosis of osteoporosis. Maturitas 2008, 59:226-233.

doi:10.1186/1471-2318-10-S1-L7

Cite this article as: Campisi: The pathophysiology of aging bone jaw: primary and secondary prevention. BMC Geriatrics 2010 10(Suppl 1):L7.
Submit your next manuscript to BioMed Central and take full advantage of:

- Convenient online submission

- Thorough peer review

- No space constraints or color figure charges

- Immediate publication on acceptance

- Inclusion in PubMed, CAS, Scopus and Google Scholar

- Research which is freely available for redistribution

Submit your manuscript at www.biomedcentral.com/submit
C Biomed Central 